\title{
STANDARDIZATION OF A TRADITIONAL POLYHERBAL FORMULATION WITH PHARMACOGNOSTIC STUDY; ITS PHYTOCHEMICAL CONTENT, ANTIOXIDANT, AND ANTIDIABETIC ACTIVITY
}

\author{
ARUNIKA SUBBA, PALASH MANDAL* \\ Plant Physiology and Pharmacognosy Research Laboratory, Department of Botany, University of North Bengal, Rajarammohunpur, \\ Shivmandir, Siliguri, West Bengal, India. Email: pmandalbotppprl@nbu.ac.in
}

Received: 21 February 2019, Revised and Accepted: 03 April 2019

\begin{abstract}
Objective: Pharmacognostic study, evaluation of antioxidant and antidiabetic activity along with phytochemical contents of an ethnomedicine AR as it is mainly used for the treatment of arthritis and diabetes by some healers in the villages of West Sikkim.

Methods: The herbal formulation was extracted in a Soxhlet apparatus successively in ten solvents from low to high polarity. The extracts were subjected to antioxidant activity, qualitative and quantitative phytochemical estimation as well as in vitro antidiabetic activity. For pharmacognostic characterization, parameters such as fluorescence activity, physicochemical values, powder microscopy, and thin-layer chromatography (TLC) were performed. Mean values with $\mathrm{p}<0.05$ were considered significant in statistical analysis.

Results: Pharmacognostic study revealed various plants tissues. Ash values suggested the presence of earthy materials and moisture content near to the maximum range. Variation of colors was exhibited by AR in fluorescence analysis. TLC expressed the presence of phytoconstituents and the $\mathrm{R}_{f}$ values were noted down to be used in the future for authentication of the sample. Potential antioxidant capacity was observed in AR, phenolics significantly contributing in 1,1-diphenyl-2-picrylhydrazyl scavenging activity, 2, 2'-azinobis (3-ethylbenzothiazoline-6-sulfonic acid) ${ }^{+}$scavenging activity and reducing power. Non-polar solvent showed the presence of alkaloid and steroids. The antidiabetic activity was very high in some extracts of AR with acetone extract showing the highest enzyme inhibiting activity. $\mathrm{IC}_{50}$ of acetone extract was $0.26 \pm 0.003 \mathrm{mg} / \mathrm{ml}$.
\end{abstract}

Conclusion: Overall study established a basic reference for the formulation AR. It was considered to possess antioxidant activity, but the interesting part of the study was its antidiabetic activity which is needed to be validated with in vivo studies and toxicity assessment.

Keywords: Ethnomedicine, Pharmacognosy, Antioxidant, Antidiabetic, Phytochemical.

(c) 2019 The Authors. Published by Innovare Academic Sciences Pvt Ltd. This is an open access article under the CC BY license (http://creativecommons. org/licenses/by/4. 0/) DOI: http://dx.doi.org/10.22159/ajpcr.2019.v12i5.32725

\section{INTRODUCTION}

Medicinal plants have always been an important part of human life. Numerous plants have established its identity in the development of novel drugs. The synthetic drugs are effective and have dominated the world of medicine, but it has also brought harmful side effects along with it. Natural sources of drugs are the only alternative to this problem which can be fulfilled through the search of medicinal plants with potential therapeutic activity. Reactive oxygen species (ROS) such as superoxide (SO) ions and hydroxyl radicals, and hydrogen peroxide when accumulated in the body initiates the development of various degenerative or pathological processes including aging, cancer, heart disease, Alzheimer's disease, neurodegenerative disorders, atherosclerosis, and diabetes [1]. Antioxidants control the damage caused by ROS which scavenges and reduces the formation of free radicals [2]. The therapeutic property of several medicinal plants is generally credited to the secondary metabolites present in them bearing antioxidant activity. In fact, dietary intake of antioxidant-rich food is believed to be inversely related to the human disease [3]. Butylated hydroxytoluene and butylated hydroxyanisole are common synthetic antioxidants which along with beneficial properties give side effects that might cause health hazards in a long-term basis. Plant-based antioxidants are preferred over synthetic ones due to safety concern [4]. Hence, research regarding plants rich in antioxidants is vital as it not only provides information about antioxidant supplement but also helps in the selection of plants for the development of novel drugs from natural sources.

Sikkim is a small Himalayan state of Northeast India which is also considered to possess numerous medicinal plants with a large number of indigenous people still depending on traditional medicine mainly from plant sources. In the present study, we have collected a polyherbal formulation from an herbal practitioner of the West district of Sikkim which was used for the treatment of arthritis and high blood sugar. We have abbreviated the formulation as "AR." It was prepared from three plants including the whole plant of Viscum articulatum Burm. f., rhizome of Rheum acuminatum Hooker. f., and Thomson and rhizome of Astilbe rivularis Buch.-Ham.ex D. Don. These plant parts were mixed and stored in powder form. It is a common fact that the collection of medicinal plants often faces the challenge of standardization. Since the therapeutic value of medicinal plants depends on the quality and quantity of chemical constituents, it is essential to standardize each and every ethnomedicine used by man. This can be achieved by a pharmacognostic study which includes parameters that help to authenticate the drug even in dry powder form after losing its morphological characteristics where there is a high risk of adulteration.

Considering the current need for research on ethnomedicine, this work has focused on the evaluation of the antioxidant activity of sample $\mathrm{AR}$ along with the pharmacognostic activity. An herbal formulation is considered to be multifunctional as it is usually found in folk medicine that a single plant may be used as a remedy for different ailments. Considering this fact, we have also carried out in vitro antidiabetic activity of the sample due to the growing demand of antihyperglycemic substance in the present world where diabetes has affected a large number of the population without any cure to it. Another important reason for carrying out the antidiabetic activity of AR is due to a considerable relation between diabetes and arthritis as people with 
diabetes are more likely to have arthritis. A major effect of diabetes includes musculoskeletal changes leading to pain in joint and stiffness with swelling, nodules under the skin, painful shoulders, and feet. Diabetes for a longer period of time may cause joint damage called arthropathy. $>26 \%$ of adults over 65 are estimated to have diabetes mellitus and diabetes is a key mortality predictor in patients with rheumatoid arthritis as reported by The Centers for Disease Control and Prevention $[5,6]$. Thus, control of diabetes may also be considered as a preventive measure to decrease the risk of arthritis.

\section{MATERIALS AND METHODS}

\section{Plant material}

A polyherbal formulation was prepared by mixing the rhizomes of $R$. acuminatum, A. rivularis, and whole plant of $V$. articulatum in equal ratio. This formulation was collected from Uttarey, West Sikkim from a herbal practitioner in March 2014. The herbarium specimens were identified and authenticated by Dr. A.P. Das, Professor, Taxonomy and Environmental Biology Laboratory, Department of Botany, University of North Bengal. The voucher specimens were deposited at laboratory herbarium; Taxonomy and Environmental Biology Laboratory, University of North Bengal against accession no 06502/Tag no. E.S. 08 for A. rivularis Buch.-Ham.ex.D.Don, 06501/Tag no. E.S. 06 for R. acuminatum Hook.f. and Thomson, and 09727/Tag no. E.S. 02 for V. articulatum Burm.f.

\section{Extraction}

Dry powder of AR was extracted through Soxhlet apparatus in ten different solvents successively beginning from non-polar solvent to polar. The extraction was started with hexane (ARHx), heptane (ARHp), benzene (ARBz), ethyl acetate (AREa), chloroform (ARCl), acetone (ARAc), butanol (ARBu), ethanol (AREa), methanol (ARMt), and aqueous (ARAq). These extracts were dried completely and reconstituted in methanol which afterward was stored in the brown bottle for qualitative and quantitative phytochemical estimation along with the antioxidant and antidiabetic activity. Dry powder was used for the pharmacognostic study.

\section{Pharmacognostic study \\ Organoleptic tests}

The powder of AR was tested with our sense organs for color, odour, appearance, texture, and taste [7].

\section{Powder microscopy}

The powder of AR was observed under a microscope after staining it with specific stains to observe the fragments of tissues on the basis of standard procedures [8]. The powder was mounted on a glass slide with glycerine and observed under a microscope. To identify the lignified tissues, the powder was stained with alcoholic phloroglucinol solution and conc. $\mathrm{HCl}$. Starch grains were identified with iodine solution (N/10). Sudan III was used for staining any oil globules if present.

\section{Physicochemical analysis}

The determination of physicochemical constants such as ash values (total ash, water-soluble ash, and acid insoluble ash), extractive values (water and alcohol), $\mathrm{pH}$ values, and moisture content was evaluated [9].

\section{Fluorescence analysis}

The chemicals present in plants show fluorescence when it was exposed to ultraviolet (UV) light which can be used as a tool to identify plants even in powder form. AR was treated with some chemical reagents to attain fluorescence. The variation in colors was noted down under visible and UV (254 nm and $365 \mathrm{~nm}$ ) light [10].

\section{Thin-layer chromatography (TLC)}

The protocol of Wagner and Bladt [11] was followed for the identification of active phytoconstituents present in AR. Readymade TLC plates coated with silica gel 60 F-254 purchased from Merck
Germany was used. Specific detection reagents were used for the identification of compounds. The developed TLC plates were observed under UV-254 nm and UV-365 nm light. DSLR Nikon camera (D-3200) was used to take pictures and the $\mathrm{R}_{\mathrm{f}}$ values of the appeared bands were calculated with the following formula:

$$
\mathrm{Rf}=\frac{\text { Distance travelled by solute }}{\text { Distance travelled by solvent }}
$$

\section{Qualitative estimation of phytochemical}

The presence of phytochemicals such as amino acids, tannins, triterpenoids, steroids, alkaloids, and flavonoids present in different solvent extracts of AR was detected according to the standard methods [12-15].

\section{Quantitative estimation of phytochemical}

\section{Total phenol content (TPC)}

TPC in AR was determined using the Folin-Ciocalteu assay [16]. The extracts of AR (1 ml) were used on which $1 \mathrm{ml} \mathrm{95 \%} \mathrm{ethanol,} 5 \mathrm{ml}$ distilled water, and $0.5 \mathrm{ml} 50 \%$ Folin-Ciocalteu were added. After $5 \mathrm{~min}$ of incubation, $1 \mathrm{ml} 5 \%$ sodium carbonate was added. The mixture was incubated for $1 \mathrm{~h}$ and absorbance was taken in UV-spectrophotometer at $725 \mathrm{~nm}$. The phenol content was calculated and expressed as $\mathrm{mg}$ gallic acid equivalents (GAE).

\section{Total flavonoids content (TFC)}

TFC of AR was calculated by the aluminum chloride colorimetric assay [17]. To $0.5 \mathrm{ml}$ of methanolic sample, $4 \mathrm{ml}$ of distilled water was added followed by $0.3 \mathrm{ml}$ of $5 \%$ sodium nitrite. It was incubated for $5 \mathrm{~min}$ followed by the addition of $0.3 \mathrm{ml} \mathrm{10 \%}$ aluminum chloride and incubated again for $6 \mathrm{~min}$. At last, $2 \mathrm{ml}$ of $1 \mathrm{M}$ sodium hydroxide was added and the mixture was diluted with $2.4 \mathrm{ml}$ distilled water. Absorbance was taken at $515 \mathrm{~nm}$. Standard curve of quercetin was prepared for the calculation of TFC of the extracts which were expressed as mg quercetin/g extractive (QE) weight.

\section{Total orthodihydric phenol content (TOPC)}

The procedure of Kim et al. [18] was followed for the measurement of TOPC of AR. The methanolic extract $(0.5 \mathrm{ml})$ was added in a test tube in which $0.5 \mathrm{ml}$ of $0.05 \mathrm{~N} \mathrm{HCl}$ and $0.5 \mathrm{ml}$ of Arnow's reagent was added. The mixture was shaken well in a vortex after which $5 \mathrm{ml}$ of distilled water and $1 \mathrm{ml}$ of $1 \mathrm{~N}$ sodium hydroxide was added. The appearance of pink color indicated the presence of TOPC, the absorbance of which was taken at $515 \mathrm{~nm}$. The TOPC was expressed in terms of catechol equivalents.

\section{Alkaloid content $(A C)$}

AC was determined by the method based on the reaction between bromocresol green (BCG) and alkaloid of the sample [19]. The methanolic extracts were evaporated and $0.5 \mathrm{ml} 2(\mathrm{~N}) \mathrm{HCl}$ was added filtered and washed with $2 \mathrm{ml}$ chloroform. BCG solution $(2.5 \mathrm{ml})$ and phosphate buffer $(2.5 \mathrm{ml}, \mathrm{pH}-4.7)$ were added to the chloroform. The mixture was thoroughly mixed by vortexing. The chloroform part (yellow color) was taken for measurement at $470 \mathrm{~nm}$. AC was expressed as solasodine equivalents (SE).

\section{Tannin content (TC)}

It was determined in AR by the Folin-Denis reagent [20]. To $0.1 \mathrm{ml}$ of extract, $7.5 \mathrm{ml}$ of distilled water was added followed by $0.5 \mathrm{ml}$ of FolinDenis reagent and $1 \mathrm{ml}$ of sodium carbonate solution. After incubation of $30 \mathrm{~min}$ in room temperature, the absorbance of the blue color mixture was taken at $700 \mathrm{~nm}$. Tannic acid was used for the preparation of standard curve and TC was expressed as tannic acid equivalents.

\section{Steroid content (SC)}

Steroid was estimated by the method of Naik and Mishra [21]. To $1 \mathrm{ml}$ of the sample extract, $4 \mathrm{ml}$ of chloroform was added and mixed thoroughly. Chloroform layer $(1 \mathrm{ml})$ was taken and evaporated completely. 
Liebermann-Burchard reagent $(2 \mathrm{ml})$ was added to it and mixed well in a vortex. The mixture was kept in the dark for $20 \mathrm{~min}$. The formation of a green colored complex confirmed the presence of steroids in the sample. Absorbance was taken at $640 \mathrm{~nm}$. SC was expressed as SE.

\section{Evaluation of antioxidant activity}

1,1-diphenyl-2- picrylhydrazyl scavenging activity (DPPH)

The ability of the extracts to scavenge DPPH free radical was carried out by the method described by Blois [22]. DPPH solution ( $2 \mathrm{ml}$ ) was added to $0.2 \mathrm{ml}$ of methanolic extracts. Absorption was taken at $517 \mathrm{~nm}$. IC $\mathrm{C}_{50}$ values were calculated from the inhibition percentage against concentration curve. Percentage inhibition was calculated by the following formula:

$$
\text { Inhibition percentage }=\frac{(\text { Absorbance of sample) }}{\text { Absorbance of control }} \times 100
$$

\section{2, 2'-azinobis (3-ethylbenzothiazoline-6-sulfonic acid) (ABTS) diammonium salt scavenging activity}

$\mathrm{ABTS}^{+}$solution $(2 \mathrm{ml})$ was added to $1 \mathrm{ml}$ of extract, incubated for $10 \mathrm{~min}$ and scavenging activity was measured by taking optical density (OD) values at $734 \mathrm{~nm}$ [23]. Inhibition percentage was calculated.

\section{Superoxide (SO) scavenging activity}

$\mathrm{SO}$ of AR was measured by the reduction of nitro blue tetrazolium (NBT) chloride according to the method of Nishikimi et al. [24]. The reaction mixture containing $1 \mathrm{ml}$ sample, $1 \mathrm{ml}$ NBT $(312 \mu \mathrm{M}), 1 \mathrm{ml}$ nicotinamide dinucleotide trihydrochloride, and $10 \mu \mathrm{l}$ phenazine methosulfate was incubated for $30 \mathrm{~min}$ under the exposure to fluorescent light. Absorbance was taken at $560 \mathrm{~nm}$. Percentage inhibition was calculated.

\section{Nitric oxide (NO) scavenging activity}

Nitrite ions are generated when NO produced by sodium nitroprusside reacts with oxygen. These nitrite ions are detected by Greiss reagent turning the reaction mixture dark pink in color [25]. The scavenging activity of NO is measured at $540 \mathrm{~nm}$. Percentage inhibition was calculated.

\section{Metal chelating $(M C)$ activity}

Ferrous ion chelation activity of AR was measured by the method of Dinis et al. [26]. In the methanolic extract $(0.4 \mathrm{ml}), 1.6 \mathrm{ml}$ of methanol was added. After that $0.04 \mathrm{ml}$ of $2 \mathrm{mM}$ ferrous chloride and $0.80 \mathrm{ml}$ of $5 \mathrm{mM}$ ferrozine were added. It was incubated at room temperature for $10 \mathrm{~min}$. Absorbance was taken at $562 \mathrm{~nm}$. Percentage inhibition was calculated.

\section{Ferric reducing antioxidant power (FRAP)}

A green colored complex was formed by the reaction among potassium ferricyanide, trichloroacetic acid, and ferric chloride. Increase in the absorbance indicates more antioxidant activity. The OD values were taken at $700 \mathrm{~nm}[27]$.

\section{Antidiabetic activity}

Alpha-glucosidase inhibiting (AGI) activity

The antidiabetic activity of AR extracts was determined by AGI activity [28]. The methanolic samples were dried completely and reconstituted in distilled water for the assay. Phosphate buffer $(6.8 \mathrm{pH})$, $0.1 \mathrm{ml} 3 \mathrm{mM}$ glutathione reduced and $0.1 \mathrm{ml} \alpha$-glucosidase $(1 \mathrm{U} / \mathrm{ml})$ taken in a test tube was incubated for $15 \mathrm{~min}$ at $37^{\circ} \mathrm{C}$. Extract $(0.5 \mathrm{ml})$ and $0.25 \mathrm{ml} \rho$-NPG were added as a substrate, and it was incubated again for $15 \mathrm{~min}$ at $37^{\circ} \mathrm{C}$. When the incubation was complete, $4 \mathrm{ml}$ sodium carbonate was added on the reaction mixture. The absorbance was taken at $405 \mathrm{~nm}$. Percentage inhibition was calculated.

\section{Statistical analysis}

The experiments were performed with triplicates. MS Excel 2007 (Microsoft, Redmond, WA, USA) was used for determining antioxidant and antidiabetic attributes. The means were compared by Duncan's multiple range test through DSAASTAT software (version 1.002). Values with $\mathrm{p}<0.05$ were considered significant. IC $_{50}$ values of antioxidants and antidiabetic activity and their standard error of estimates were done in Smith's Statistical Package version 2.5 (prepared by Gary Smith, CA, USA). Correlation coefficient analysis was done using SPSS (Version 12.00, SPSS Inc., Chicago, IL, USA) and principal component analysis (PCA) was conducted in XLSTAT 2014.

\section{RESULTS}

\section{Pharmacognostic study}

Organoleptic tests revealed that the powder of AR was brown in color, slightly bitter in taste; texture slightly rough and it had no characteristic odor. Microscopic analysis of the powdered sample showed various tissues such as starch granules, calcium oxalate crystals, xylem vessels, parenchymatous cells, sclereids, and stone cells
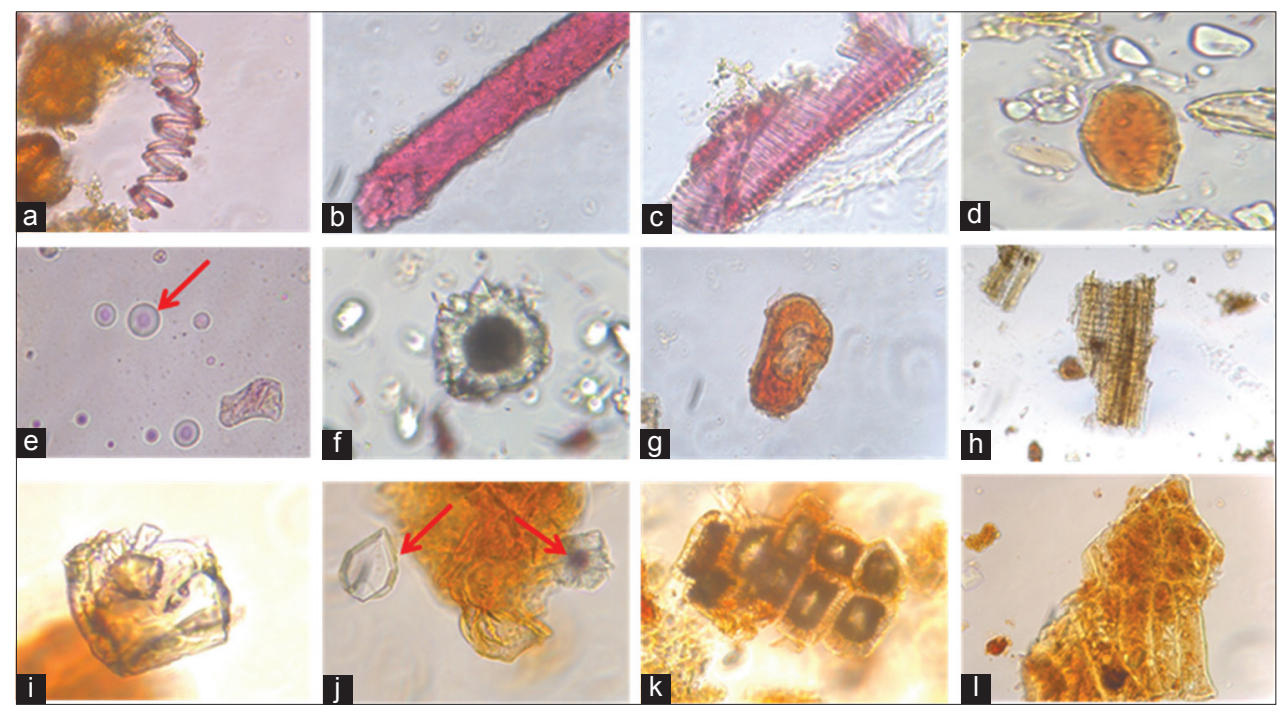

Fig. 1: Powder microscopy of AR. (a) spiral xylem vessels, (b) vessels with pits, (c) scalariform tracheid, (d) oil globule, (e) starch grains with concentric hilum, (f) cluster of calcium oxalate crystals, (g) stone cells, (h) medullary rays with fibers, (i) cuboidal shaped crystal, (j) crystals, (k) sclereids, (l) parenchymatous cells 


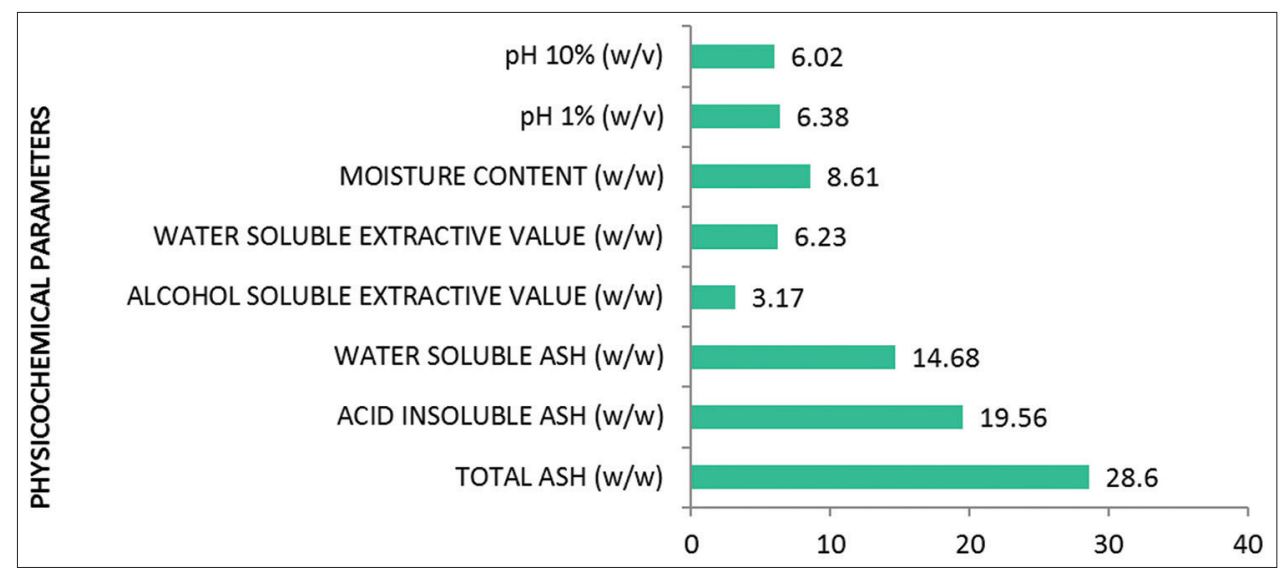

Fig. 2: Physicochemical study of powder polyherbal formulation, AR.

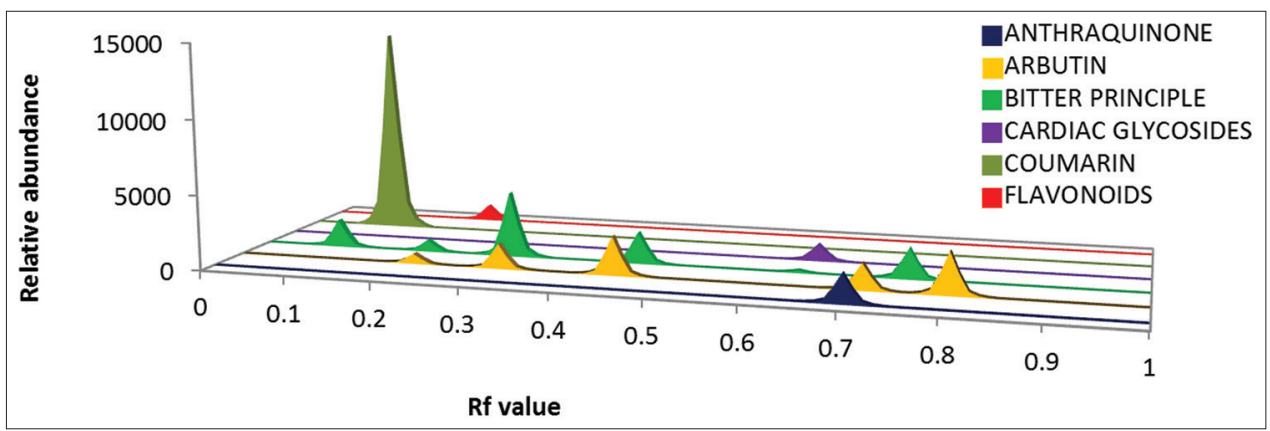

Fig. 3: Relative abundance against Rf values graph of the phytoconstituents identified in thin-layer chromatography plates of AR

Table 1: Fluorescence analysis of AR under visible and UV light. Colors were compared to the standard color chart of RAL (Reichs-Ausschuß für Lieferbedingungen and Gütesicherung)

\begin{tabular}{llll}
\hline S. No. & Reagents & Visible & UV-254 nm \\
\hline 1 & Powder+distilled water & Yellow orange & Colorless \\
2 & Powder+50\% KOH & Brown red & Colorless \\
3 & Powder+benzene & Colorless & Colorless \\
4 & Powder+50\% benzene & Lemon yellow & Honey yellow \\
5 & Powder+chloroform & Lemon yellow & Broom yellow \\
6 & Powder+50\% chloroform & Broom yellow & Curry yellow \\
7 & Powder+nitric acid (conc.) & Daffodil & Colorless \\
8 & Powder+50\% nitric acid & Honey yellow & Colorless \\
9 & Powder+10\% ferric chloride & Curry yellow & Colorless \\
10 & Powder+methanol & Honey yellow & Colow beige \\
11 & Powder+50\% methanol & Broom yellow & Colorless \\
12 & Powder+ethanol & Daffodil yellow & Colorless \\
13 & Powder+50\% ethanol & Broom yellow & Grey beige \\
14 & Powder+glacial acetic acid (conc.) & Lemon yellow & Vurry yellow \\
15 & Powder+50\% glacial acetic acid & Lemon yellow & Sapphire blue \\
16 & Powder+sulfuric acid (conc.) & Copper brown & Curry yellow \\
17 & Powder+50\% sulfuric acid & Beige & Honey yellow \\
\hline UV: Ultraviolet & & & Granite grey
\end{tabular}

(Fig. 1). The physicochemical analysis showed the different parameters of quality control which is illustrated in Fig. 2. Table 1 represents the variation of colors exhibited by AR under UV light after treatment with different chemical reagents. TLC of AR revealed the presence of some phytoconstituents such as anthraquinone, arbutin, flavonoids, cardiac glycosides, coumarins, and bitter principles. The $\mathrm{R}_{\mathrm{f}}$ values and relative abundance are calculated and are presented in Table 2 and Fig. 3.

\section{Qualitative phytochemical estimation}

Phytochemical screening of different solvent extracts of AR was performed based on standard tests. Some bioactive phytochemicals such as phytosterol, triperpenoids, cardiac glycosides, flavonoids, reducing sugar, resin, and amino acids were present in AR (Table 3). Phytosterol and reducing sugar were present in all the extracts of AR with AREa, ARAc, ARBu, AREt, and ARMt possessing the most concentrated amount of it. Tannins and alkaloids were not detected in the sample while amino acid was present only in ARAq.

\section{Quantitative phytochemical estimation}

Most of the phytochemicals present in plants possess medicinal properties which are useful during the treatment of ailments in traditional system of medicine. Even for the development of modern drugs, these phytochemicals are essential. We have, therefore, carried out the quantitative estimation of some phytochemicals such as phenol, flavonoids, orthodihydric phenol, alkaloids, tannin, and steroids which 
Table 2: Detection of bioactive phytoconstituents in powder AR by TLC technique

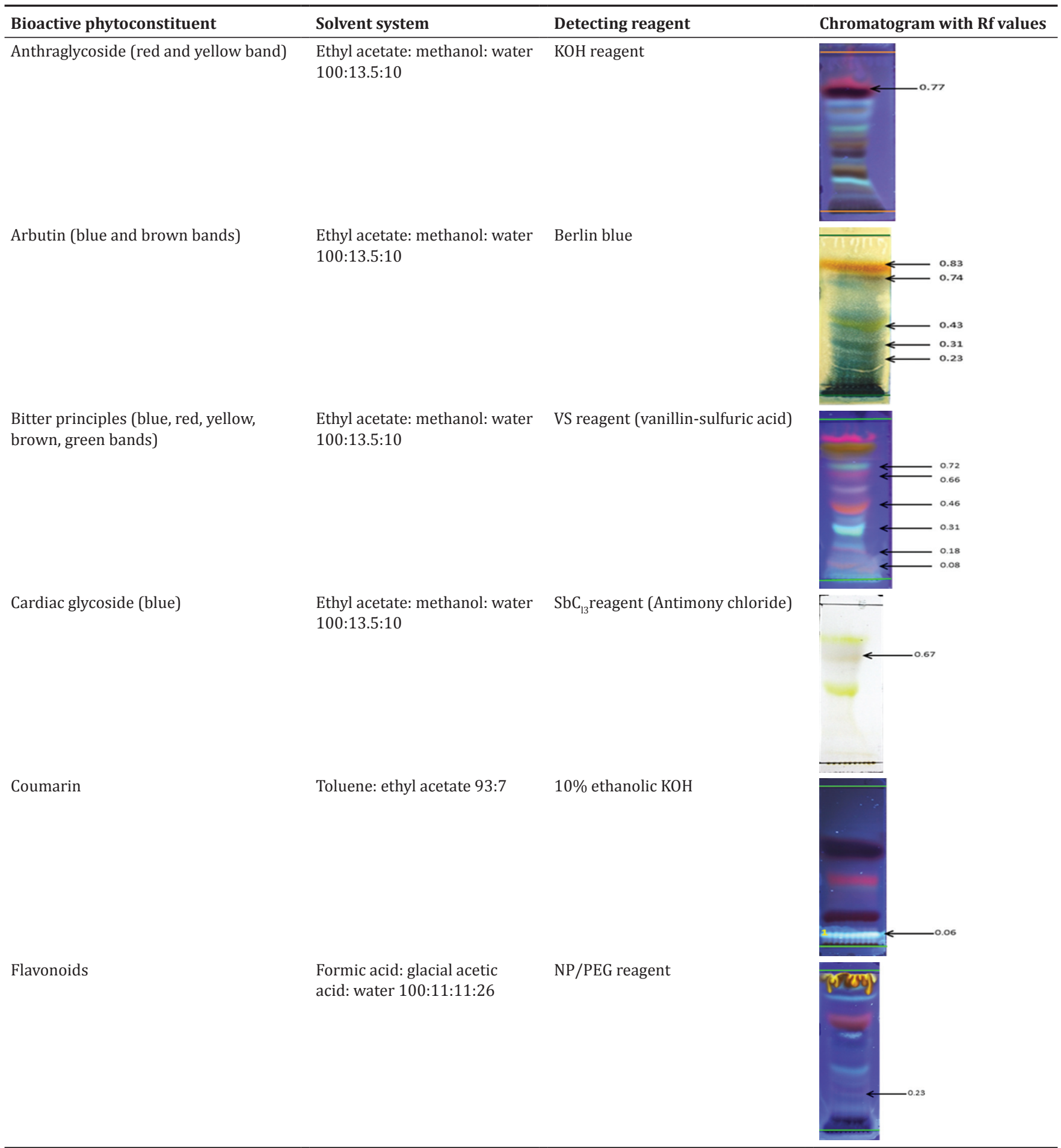

TLC: Thin-layer chromatography

are known for their health benefits. The results in Table 4 have clearly illustrated that AR is enriched with these phytochemicals especially TPC which was found in highest quantity in ARAc $(321.453 \pm 0.55 \mathrm{mg}$ GAE/g EW). TFC was concentrated mainly in AREa $(44.75 \pm 0.07 \mathrm{mg}$ QE/g EW). SC, TC, and TOPC were also detected. Alkaloids were detected only in selective solvent extracts preferably in non-polar solvents such as hexane, heptane, benzene, and ethyl acetate with ARBz exhibiting higher AC $(1.80 \pm 0.20 \mathrm{mg} \mathrm{SE} / \mathrm{g}$ EW) than the rest of the solvents. TC was again highest in ARAc with $394.423 \pm 0.31$ (mg TA/g EW).

\section{In vitro antioxidant activity}

Antioxidants are capable of scavenging free radicals and this radical scavenging activity of antioxidants present in AR is illustrated in Table 5 . The activity as represented in $\mathrm{IC}_{50}$ values with the lowest $\mathrm{IC}_{50}$ (highest antioxidant activity) in $\mathrm{DPPH}$ and $\mathrm{ABTS}^{+}$scavenging assay was exhibited by ARAc. The acetone extract was also suitable for ferric reducing potentiality (1608.073 $\pm 0.0002 \mathrm{mg}$ AAE/g EW). MC $(3.777 \pm 0.62 \mathrm{mg} / \mathrm{ml})$ and SO scavenging potential $(0.24 \pm 0.002 \mathrm{mg} / \mathrm{ml})$ were found to be highest in ARAq. 
Table 3: Qualitative phytochemical screening of AR in different solvent extracts

\begin{tabular}{|c|c|c|c|c|c|c|c|c|c|c|}
\hline Phytochemicals & ARHx & ARHp & $\mathrm{ARBz}$ & AREa & ARCl & ARAc & $\mathrm{ARBu}$ & AREt & ARMt & ARAq \\
\hline \multicolumn{11}{|l|}{ Phytosterol } \\
\hline \multicolumn{11}{|l|}{ Triterpenoids } \\
\hline \multicolumn{11}{|l|}{ Cardiac glycosides } \\
\hline \multicolumn{11}{|l|}{ Glycosides } \\
\hline \multicolumn{11}{|l|}{ Flavonoids } \\
\hline \multicolumn{11}{|l|}{ Reducing sugar } \\
\hline \multicolumn{11}{|l|}{ Resins } \\
\hline \multicolumn{11}{|l|}{ Amino acids } \\
\hline \multicolumn{11}{|l|}{ Relative abundance } \\
\hline & Low & & & Medium & & & High & & & \\
\hline
\end{tabular}

Table 4: Quantitative estimation of phytochemicals of AR

\begin{tabular}{|c|c|c|c|c|c|c|}
\hline $\begin{array}{l}\text { Solvent } \\
\text { fractions }\end{array}$ & TPC (mg GAE/g EW) & TFC (mg QE/g EW) & TOPC (mg CE/g EW) & AC (mg SE/g EW) & TC (mg TA/g EW) & SC (mg SE/g EW) \\
\hline ARHx & NA & NA & NA & $0.340 \pm 0.14_{c}$ & NA & $0.354 \pm 0.09_{b}$ \\
\hline ARHp & $20.483 \pm 0.03$ & $18.95 \pm 0.02_{\mathrm{d}}$ & $0.060 \pm 0.01_{\mathrm{e}}$ & $0.636 \pm 0.10_{b}^{c}$ & $77.190 \pm 0.01_{h}$ & $0.334 \pm 0.013_{c}$ \\
\hline $\mathrm{ARBz}$ & $93.887 \pm 0.07{ }_{\mathrm{e}}$ & $33.29 \pm 0.06_{b}$ & $0.269 \pm 0.06_{d}$ & $1.80 \pm 0.20_{a}$ & $180.619 \pm 0.04_{\mathrm{e}}$ & $0.852 \pm 0.06_{\mathrm{a}}$ \\
\hline AREa & $152.486 \pm 0.37_{\mathrm{c}}$ & $44.75 \pm 0.07_{\mathrm{a}}^{\circ}$ & $0.625 \pm 0.07_{b}^{\mathrm{b}}$ & $0.238 \pm 0.11_{d}$ & $343.231 \pm 0.29_{b}$ & $0.251 \pm 0.069_{d}$ \\
\hline $\mathrm{ARCl}$ & $91.183 \pm 0.08_{f}$ & $13.56 \pm 0.02_{\mathrm{f}}^{\mathrm{d}}$ & $0.056 \pm 0.02^{b}$ & NA & $191.22 \pm 0.02_{\mathrm{d}}$ & $0.121 \pm 0.019_{\mathrm{f}}^{\mathrm{d}}$ \\
\hline ARAc & $321.453 \pm 0.55_{\mathrm{a}}$ & $27.19 \pm 0.15_{c}$ & $1.109 \pm 0.01_{\mathrm{a}}$ & NA & $394.423 \pm 0.31_{a}$ & $0.073 \pm 0.037_{h}$ \\
\hline $\mathrm{ARBu}$ & $188.636 \pm 0.52_{\mathrm{b}}^{\mathrm{a}}$ & $18.45 \pm 0.02_{\mathrm{e}}^{\mathrm{c}}$ & $1.159 \pm 0.01_{\mathrm{a}}^{\mathrm{a}}$ & NA & $217.096 \pm 0.21_{c}^{\mathrm{d}}$ & $0.080 \pm 0.043_{g}^{\mathrm{n}}$ \\
\hline AREt & $80.781 \pm 0.51_{g}$ & $6.05 \pm 0.13_{\mathrm{g}}$ & $0.264 \pm 0.04_{d}^{d}$ & NA & $97.544 \pm 0.09_{f}$ & $0.041 \pm 0.044_{i}^{g}$ \\
\hline ARMt & $106.796 \pm 0.41_{d}$ & $0.12 \pm 0.04_{i}^{b}$ & $0.488 \pm 0.06_{c}$ & NA & $89.822 \pm 0.14 \mathrm{~g}$ & $0.145 \pm 0.044$ e \\
\hline ARAq & $64.539 \pm 0.53_{h}$ & $4.6 \pm 0.06_{h}$ & $0.284 \pm 0.04_{d}$ & NA & $6.835 \pm 0.02_{\mathrm{i}}$ & $0.032 \pm 0.055_{j}$ \\
\hline
\end{tabular}

Values with different letters ( $a, b, c, d, e, f, g, h, i$ and $j)$ are significantly ( $p<0.05)$ different from each other by Duncan's multiple range test (DMRT), NA: Not applicable, TPC: Total phenol content, TFC: Total flavonoids content, QE: Quercetin/g extractive, TOPC: Total orthodihydric phenol content, AC: Alkaloid content, TC: Tannin content, SC: Steroid content, SE: Solasodine equivalents, GAE: Gallic acid equivalents

Table 5: In vitro antioxidant activity of AR extracts

\begin{tabular}{|c|c|c|c|c|c|c|}
\hline $\begin{array}{l}\text { Solvent } \\
\text { fractions }\end{array}$ & DPPH IC $_{50}(\mathrm{mg} / \mathrm{ml})$ & $\mathrm{ABTS}+\mathrm{IC}_{50}(\mathrm{mg} / \mathrm{ml})$ & $\mathrm{SO} \mathrm{IC}_{50}(\mathrm{mg} / \mathrm{ml})$ & $\mathrm{NO} \mathrm{IC}_{50}(\mathrm{mg} / \mathrm{ml})$ & $\mathrm{MC} \mathrm{IC}_{50}(\mathrm{mg} / \mathrm{ml})$ & FRAP (mg AAE/g EW) \\
\hline ARHx & $3.087 \pm 0.22$ & $1.813 \pm 0.33$ & $2.352 \pm 0.06$ & NA & NA & $50.101 \pm 0.36$ \\
\hline ARHp & $2.501 \pm 0.02_{\mathrm{f}}^{\mathrm{g}}$ & $0.684 \pm 0.01_{d}^{e}$ & NA & NA & NA & NA \\
\hline $\mathrm{ARBz}$ & $2.615 \pm 0.07_{f}^{1}$ & $0.372 \pm 0.08_{c}^{a}$ & $0.461 \pm 0.04_{b c}$ & $2.139 \pm 0.02_{b}$ & NA & NA \\
\hline AREa & $0.328 \pm 0.03_{c}$ & $0.079 \pm 0.03^{c}$ & $0.613 \pm 0.19_{c}^{\mathrm{bc}}$ & NA & NA & $343.706 \pm 0.01_{d}$ \\
\hline $\mathrm{ARCl}$ & $0.986 \pm 0.02_{\mathrm{e}}^{\mathrm{c}}$ & $0.277 \pm 0.03_{\mathrm{bc}}^{\mathrm{a}}$ & $1.883 \pm 0.04^{c}$ & NA & NA & $294.514 \pm 0.06^{d}$ \\
\hline ARAc & $0.085 \pm 0.004$ & $0.043 \pm 0.01_{a}^{b c}$ & $0.904 \pm 0.02_{\mathrm{d}}^{\mathrm{e}}$ & $2.479 \pm 0.02$ & NA & $1608.07 \pm 0.001_{a}$ \\
\hline AREt & $0.331 \pm 0.05^{\mathrm{ab}}$ & $0.127 \pm 0.02^{\mathrm{a}}$ & $1.005 \pm 0.03_{d}^{b}$ & $7.399 \pm 0.38^{d}$ & $15.162 \pm 0.01_{b}^{c}$ & $346.946 \pm 0.15^{c}$ \\
\hline ARMt & $0.231 \pm 0.01_{\mathrm{bc}}^{\mathrm{c}}$ & $0.115 \pm 0.01^{\mathrm{a}}$ & $0.402 \pm 0.11^{d}$ & $3.699 \pm 0.42^{\mathrm{e}}$ & $3.974 \pm 0.01$ & $130.082 \pm 0.07_{g}^{c}$ \\
\hline ARAq & $0.588 \pm 0.07$ & $0.138 \pm 0.02^{a b}$ & $0.24 \pm 0.002^{b}$ & NA & $3.777 \pm 0.61$ & $167.153 \pm 0.01_{f}^{\mathrm{g}}$ \\
\hline STD & $0.11 \pm 0.01_{\mathrm{ab}}^{\mathrm{d}}(\mathrm{AA})$ & $0.28 \pm 0.001_{\mathrm{bc}}^{\mathrm{ab}}(\mathrm{AA})$ & $0.03 \pm 0.011_{a}^{a}(\mathrm{AA})$ & $0.03 \pm 0.002_{\mathrm{a}}(\mathrm{CC})$ & $0.01 \pm 0.001_{\mathrm{a}}^{\mathrm{a}}(\mathrm{BHT})$ & \\
\hline
\end{tabular}

AA: Ascorbic acid; CC: Curcumin; BHT: Butylated hydroxytoluene, Values with different letters (a, b, c, d, e, f, g and h) are significantly (p<0.05) different from each other by Duncan's multiple range test (DMRT), NA: Not applicable, STD: Standard, DPPH: 1,1-diphenyl-2-picrylhydrazyl scavenging activity, SO: Superoxide, NO: Nitric oxide, MC: Metal chelating, FRAP: Ferric reducing antioxidant power, ABTS: 2, 2'-azinobis (3-ethylbenzothiazoline-6-sulfonic acid)

\section{Antidiabetic activity}

The antidiabetic activity of AR extracts was evaluated by the inhibition of the $\alpha$-glucosidase enzyme. Some of the extracts showed potential antidiabetic activity when compared with standard drug metformin (Fig. 4). Inhibition of enzyme by some extracts of AR were remarkable while some extracts showed no inhibition at all. Some of the extracts showing good inhibition were ARAc, AREa, and ARBu with ARAc exhibiting highest antidiabetic activity $(0.26 \pm 0.003 \mathrm{mg} / \mathrm{ml})$. The $\mathrm{IC}_{50}$ value of metformin (standard) was $0.175 \pm 0.03 \mathrm{mg} / \mathrm{ml}$.

\section{DISCUSSION}

Folk medicine is one of the oldest forms of health-care system that has proved its efficacy to the test of time. The growing interest in search of natural source of medicine has opened a scope for folk medicine to be recognized globally. The herbal medicine is usually found in a dried form where the parts of plants are either powder or are twisted and rolled which makes it impossible to be identified. Therefore, this work is an attempt to study an ethnomedicine (AR) which is a combination of three plants/parts which is traditionally used for the treatment of arthritic pain in a village of West Sikkim. First, we have tried to observe some diagnostic and diabetes characteristics of AR which could be used to establish a standard for this formulation for authenticity and quality control which could be helpful for preparing herbal monographs as emphasized by the WHO. Out of many tissues observed in powder microscopy, AR powder contained few prominent tissues such as a large number of starch granules with concentric hilum, different shapes of crystals, and spiral xylem vessels. The physicochemical study is another very important parameter for quality control. Total ash values are measured for the detection of adulterants such as stone, silica, and some other earthy materials [29]. Acid-insoluble ash represents the 


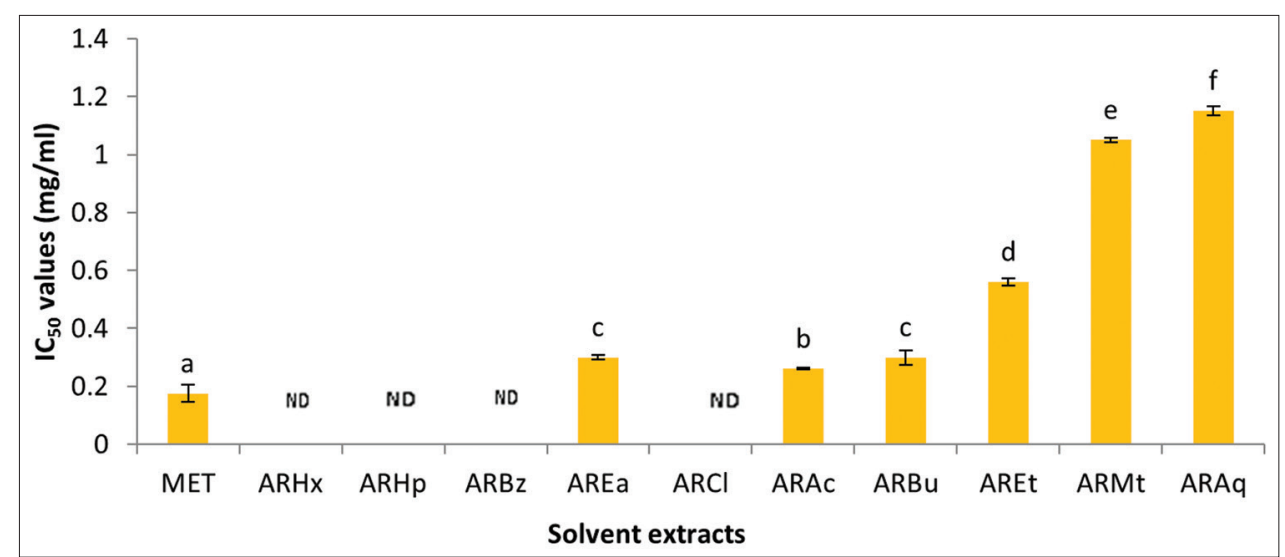

Fig. 4: Alpha-glucosidase inhibiting activity of AR compared with standard drug metformin (MET). Values with different letters (a, b, c, d, e and $f)$ are significantly $(p<0.05)$ different from each other by Duncan's multiple range test; ND: Not detected

presence of these materials which was found to be $19.56 \%(\mathrm{w} / \mathrm{w})$ and water soluble ash was $14.68 \%(\mathrm{w} / \mathrm{w})$ which indicates that sample AR should be taken more care of while handling and preparation as the amount of acid insoluble ash should be as low as possible. The moisture content of AR was $8.61 \%(w / w)$ which was within the limit of the recommended range of not exceeding $14 \%$ and thus it can be stored for a longer period of time, and there is a less probability for microbial growth. The water-soluble extractive value was higher $(6.23 \% \mathrm{w} / \mathrm{w})$ than alcohol soluble extractive $(3.17 \% \mathrm{w} / \mathrm{w})$ which suggests that water is suitable to achieve the better amount of extracts than alcohol from AR. The $\mathrm{pH}$ values are almost alkaline which is $>6$ make the formulation safer for consumption. Fluorescence is a phenomenon which is exhibited by various phytochemicals. Each chemical has a specific color which if not attained directly may reveal colors after treating with particular chemical reagents [30,31]. Moreover, this parameter is regarded as one of the important methods for assessing the quality of powder drugs. The variation of colors from AR under visible and UV light (254 $\mathrm{nm}$ and $365 \mathrm{~nm}$ ) is presented in Table 1. The variation in colors may also indicate the diversity of chemical compounds present in the sample [32]. Another parameter we have selected for standardization of AR is through TLC technique (Table 2 and Fig. 3). It is usually performed to develop a basic idea for the presence of some active phytoconstituents in the sample. The $R_{f}$ values of the bands representing a compound are specific if carried out in the same solvent system and detection reagents. Thus, it can be useful for the quality check of the same formulation in the future. The detail of the solvent system and detection reagents along with the developed chromatogram images is summarized in Table 2. TLC has not only provided the qualitative data of the phytochemicals but also offer the quantitative profile of the phytoconstituents present with relative abundance as given in Fig. 3. Several bands of arbutin and bitter principles were observed, but coumarin showed the highest relative abundance which indicates the quantity of the particular phytoconstituent. Hence, TLC serves as an important tool for the preliminary evaluation of a crude drug[11]. Since the therapeutic activity of any medicinal plants is attributed to the various secondary metabolites present in it, thus we have carried out a qualitative screening of phytochemicals present in AR through standard tests. As the nature of phytochemical constituents present in plants is diverse, we cannot say that a particular solvent is suitable to extract all the bioactive compounds [33]. To fulfill the range of polarity we have extracted AR in 10 different solvents from nonpolar to polar as mentioned earlier. The results have also indicated that solvents play a crucial role in the extraction of compounds from plants. Table 3 justifies this point where it is clear that ethyl acetate, acetone, butanol, and methanol have concentrated the amount of phytochemicals while in case of amino acid, it was observed that only aqueous sample gave a positive result. Similarly, antioxidant activity was also highly influenced by solvent extraction methods. TPC was highest in acetone extract of AR which is supported by previous studies also [34]. AC was not detected in TLC and qualitative test with Dragendorff's reagent, but it was quantitatively observed particularly in polar solvents up to ethyl acetate. It may also indicate that for a particular phytochemical, a single test is not efficient. More than one test should be performed for a single phytochemical test. The analysis of physicochemical and phytochemical attributes mainly helps to evaluate the phytoconstituents present in a particular extract and to find the solubility of a particular constituent in a specific solvent [35]. Plants produce antioxidants in the form of secondary metabolites such as phenolics and flavonoids to cope up with the stress caused by ROS [36]. The activity of these antioxidants of AR was evaluated through free radical scavenging activity where it was observed that some of the extracts of AR showed better DPPH and $\mathrm{ABTS}^{+}$scavenging activity than standard ascorbic acid. Here again, acetone extract was found to be the best when compared to other extracts as it also showed the highest reducing powder. In case of reducing power, it was observed that the range of activity was aqueous $<$ methanol<ethanol<acetone but after that, it again decreased as it proceeded further toward non-polar solvents. This may be due to the fact that the nature of compounds responsible for reducing power ranges in moderately polar solvents.

The antidiabetic activity was evaluated by hindering the absorption of glucose through inhibition of the carbohydrate hydrolyzing enzyme, $\alpha$-glucosidase, in the digestive tract. Again acetone extract exhibited the highest inhibition of $\alpha$-glucosidase enzyme (Fig. 4) which was quite close to standard drug metformin. It shows that AR has a potential antidiabetic activity which could be further explored with broader parameters of toxicity and in vivo models.

\section{Correlation}

The Pearson correlation was analyzed to carry out the relationship amongst antioxidant activity, antidiabetic activity with its phytochemicals content (Table 6). It showed a significant positive correlation between $\mathrm{DPPH}$ and $\mathrm{ABTS}^{+}$scavenging activity $(\mathrm{p}<0.01)$ and a significant negative correlation for DPPH to TPC and TOPC, respectively. Since this indicates that the increase in TPC and TOPC will decrease the $\mathrm{IC}_{50}$ values of DPPH, it is clear that the group of phenols present in AR is responsible for the scavenging activity of DPPH and $\mathrm{ABTS}^{+}$. Several such reports are available where phenols were considered having antioxidant activity with the scavenging potentiality of free radicals $[37,38]$. Antioxidant of phenolics is often attributed to its redox potentiality allowing them to act as hydrogen donors, singlet oxygen scavengers, and redox agents [39]. The mechanism of the Folin-Ciocalteu method is based on the reducing properties of phenolic compounds. This is evident in our study also where a strong positive correlation was observed between TPC, TOPC, and reducing power (FRAP) with significant $\mathrm{p}<0.01$. TC showed a significant positive correlation with alkaloid and steroid content, but none of these showed any correlation with the antioxidant activity that we had carried out in our study. It is possible that the presence of these compounds was not particularly responsible for the antioxidant activity of AR. The antidiabetic activity was prominent in this study, but none of the phytochemicals we 
Table 6: Pearson correlation matrix of antioxidant and antidiabetic activity of AR extracts

\begin{tabular}{|c|c|c|c|c|c|c|c|c|c|c|c|c|}
\hline & DPPH & ABTS & So & No & MC & FRAP & TPC & TFC & TOPC & AC & TC & SC \\
\hline ABTS & $0.819^{* *}$ & & & & & & & & & & & \\
\hline SO & 0.291 & 0.604 & & & & & & & & & & \\
\hline NO & -0.467 & -0.398 & -0.174 & & & & & & & & & \\
\hline MC & -0.474 & -0.330 & -0.206 & $0.855^{* *}$ & & & & & & & & \\
\hline FRAP & -0.536 & -0.375 & -0.003 & 0.175 & 0.055 & & & & & & & \\
\hline TPC & $-0.659 *$ & -0.603 & -0.178 & 0.291 & 0.112 & $0.934^{* *}$ & & & & & & \\
\hline TFC & -0.112 & -0.366 & -0.300 & -0.151 & -0.253 & 0.409 & 0.562 & & & & & \\
\hline $\mathrm{AC}$ & $0.709^{*}$ & 0.363 & -0.302 & -0.343 & -0.356 & -0.386 & -0.442 & 0.152 & -0.422 & & & \\
\hline TC & 0.577 & 0.120 & -0.014 & -0.379 & -0.435 & -0.315 & -0.314 & 0.182 & -0.493 & $0.690 *$ & & \\
\hline SC & 0.615 & 0.169 & 0.008 & -0.397 & -0.431 & -0.351 & -0.361 & 0.154 & -0.527 & $0.703^{*}$ & $0.998^{* *}$ & \\
\hline AGI & -0.170 & -0.167 & -0.305 & -0.239 & 0.027 & -0.135 & -0.186 & -0.296 & -0.127 & -0.201 & -0.251 & -0.236 \\
\hline
\end{tabular}

${ }^{* *}$ Correlation is significant at the 0.01 level (2-tailed), ${ }^{*}$ Correlation is significant at the 0.05 level (2-tailed), DPPH: 1,1-diphenyl-2-picrylhydrazyl scavenging activity, APTS: 2, 2'-azinobis (3-ethylbenzothiazoline-6-sulfonic acid), SO: Superoxide, NO: Nitric oxide, MC: Metal chelating, FRAP: Ferric reducing antioxidant power, TPC: Total phenol content, TFC: Total flavonoids content, TOPC: Total orthodihydric phenol content, AC: Alkaloid content, TC: Tannin content, SC: Steroid content, AGI: Alpha-glucosidase inhibiting

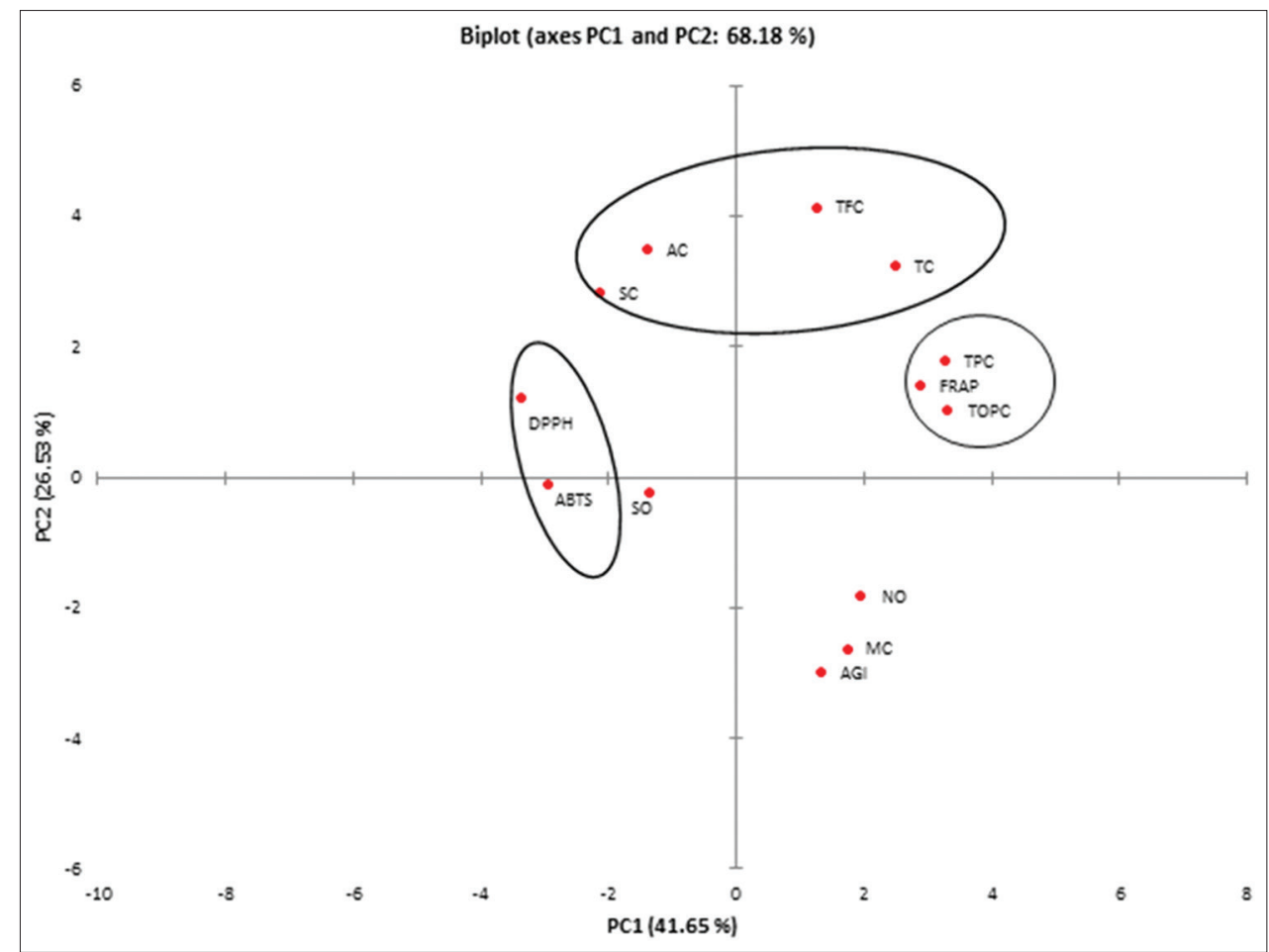

Fig. 5: Principal component analysis of antioxidant, antidiabetic activity, and quantitative phytochemical estimation of AR

had tested showed any correlation for this activity. It, therefore, pointed toward the diverse and complex nature of phytochemicals which are present in plants performing their specific functions. Perhaps AR contains other active phytoconstituents compounds which were responsible for the antidiabetic activity as reported here.

\section{PCA}

PCA is the simplest of the multivariate statistical analyses through which the primary pattern of the multiple variables in an experiment can be visualized [40]. In this study, PCA was analyzed to observe the overall relationship of antioxidants, antidiabetic activities, and phytochemicals detected quantitatively in AR. First and second principal components (PC1 and PC2) accounted for $41.65 \%$ and $26.53 \%$ of the variance, respectively, totalizing $68.18 \%$ (Fig. 5). The loading plot displays the association of different variables with each other. The loading plot showed that TPC, TOPC, and FRAP were loaded positively on PC1 with squared cosine values of $0.7712,0.7949$, and 0.6027 , respectively. TFC, AC, TC, and SC were loaded positively on PC2 with squared cosine values of 0.7921 , $0.5624,0.4831$, and 0.3723 , respectively. The cluster of DPPH and ABTS lies in the opposite direction to the cluster of TPC, TOPC, and FRAP which indicates that they are negatively correlated with each other. It is also supported by the above result of Pearson correlation analysis. Wang and $\mathrm{Hu}$ [41] performed PCA with antioxidant attributes of mulberry fruits where similar clusters were formed with TPC, ferric reducing power and oxygen radical absorbance capacity being positively loaded on PC1 [42].

\section{CONCLUSION}

Our study has attempted to establish a standard for an ethnomedicine AR. This can be used as a basic reference of this powder formulation which could be easily optimized, cheaper, and authentic and reproducible. Further standardization techniques might also be suggested which can be done with sophisticated analytical instruments such as gas chromatography-mass spectrometry, Fourier transform infrared, and nuclear magnetic resonance for the comprehensive study, but the cost of analysis would be much higher. We were also able to explore its antidiabetic activity along with the influence of solvents on the extraction compounds specifically for a particular activity. AR 
showed potential antioxidant capacity along with antidiabetic activity which could further be explored in an animal model.

\section{ACKNOWLEDGMENT}

We are grateful to the UGC for providing financial support under the scheme of Rajiv Gandhi National Fellowship. We would also like to acknowledge the Forests, Env. and W/L Management Department Government of Sikkim, Gangtok, for providing the permit for survey in West Sikkim. We are extremely thankful toward Mr. Nar Bahadur Subba, an herbal practitioner for providing us the sample to perform this work.

\section{AUTHORS' CONTRIBUTIONS}

Palash Mandal conceived and designed the experiments, participated in the editing of the manuscript.

Arunika Subba performed the experiments and participated in the analysis of data and writing of the manuscript.

\section{CONFLICTS OF INTEREST}

Authors declare no conflicts of interest.

\section{REFERENCES}

1. Huang DH, Chen C, Lin C, Lin Y. Antioxidant and antiproliferative activities of water spinach (Ipomoea aquatica Forsk.) constituents. Bot Bull Acad Sci 2005;46:99-106.

2. Yildrim A, Oktay M, Bilaloglu V. The antioxidant activity of leaves of Cydonia vulgaris. Turk J Med Sci 2001;31:23-27.

3. Khilifi S, El-Hachimi Y, Khalil A, Es-Safi N, Belahyan A, Tellal R, et al. In vitro antioxidant properties of Salvia verbenaca $\mathrm{L}$. hydromethanolic extract. Ind J Pharmacol 2006;38:276-80.

4. Akinmoladun AC, Ibukun EO, Afor E, Akinrinlola BL, Onibon TR, Akinboboye AO, et al. Chemical constituents and antioxidant activity of Alstonia boonei. Afr J Biotechnol 2007;6:1197-201.

5. Innala L, Möller B, Ljung L, Magnusson S, Smedby T, Södergren A, et al. Cardiovascular events in early RA are a result of inflammatory burden and traditional risk factors: A five year prospective study. Arthritis Res Ther 2011;13:R131.

6. Michaud K, Wolfe F. Comorbidities in rheumatoid arthritis. Best Pract Res Clin Rheumatol 2007;21:885-906.

7. Kokate CK, Purohit AP, Gokhale SB. Text Book of Pharmacognosy. $18^{\text {th }}$ ed. Pune: Nirali Prakashan; 2002.

8. Lala PK. Practical Pharmacognosy. $1^{\text {st }}$ ed. Calcutta: Lina; 1981.

9. Harborne JB. Phytochemical Methods-a Guide to Modern Techniques of Plant Analysis. Berlin: Springer Verlag; 2005.

10. Chase CR, Pratt R. Fluorescence of powdered vegetable drugs with particular reference to development of a system of identification. J Pharm Sci 1949;38:324-31.

11. Wagner H, Bladt S. Plant Drug Analysis: A Thin Layer Chromatography Atlas. $2^{\text {nd }}$ ed. Berlin: Springer Verlag; 2009.

12. Kumar A, Ilavarasan R, Jayachandan T, Decaraman M, Aravindhan P, Padmanabhan N. Phytochemical investigation on a tropical plant, Syzygium cumini from Kattuppalayam, Erode District, Tamil Nadu, South India. Pak J Nutr 2009;8:83-5.

13. Ngbede J, Yakubu RA, Nyam DA. Phytochemical screening for active compound in Canaruim schweinfurthii (Atile) leaves from Ios North, Plateau state, Nigeria. Res J Biol Sci 2008;3:1076-8.

14. Ibrahim HA, Ibrahim H. Phytochemical screening and toxicity evaluation on the leaves of Argemone mexicana Linn. (Papaveraceae). Int J Pure Appl Sci Technol 2009;3:39-43.

15. Trease GE, Evans WC. Pharmacognosy. $13^{\text {th }}$ ed. London: Bailliere Tuidal; 1989. p. 799-80.

16. Singleton, VL, Rossi JA. Colorimetry of total phenolics with phosphomolybdic phosphotungstic acid reagents. Am J Enol Vitic 1965;16:144-58.

17. Zhishen J, Mengcheng T, Jianming W. The determination of flavonoid contents in mulberry and their scavenging effects on superoxide radicals. Food Chem 1999;64:555-9.

18. Kim DO, Jeong SW, Lee CY. Antioxidant capacity of phenolic phytochemicals from various cultivars of plums. Food Chem 2003;81:321-6.

19. Ajanal M, Gundkalle MB, Nayak SU. Estimation of total alkaloid in chitrakadivati by UV-spectrophotometer. Anc Sci Life 2012;31:198-201.

20. Thimmaiah SR. Standard Methods of Biochemical Analysis Chapter Phenolics. New Delhi India: Kalyani Publishers; 1999. p. 296-7.

21. Naik PD, Mishra RL. Quantitaive analysis of secondary metabolites of Withania somnifera and Datura stramonium. Int J Sci Res 2015;4:300-3.

22. Blois MS. Antioxidant determinations by the use of a stable free radical. Nature 1958;181:1199-200.

23. Re R, Pellegrini N, Proteggente A, Pannala A, Yang M, Rice-Evans C, et al. Antioxidant activity applying an improved ABTS radical cation decolorization assay. Free Radic Biol Med 1999;26:1231-7.

24. Nishikimi M, Appaji N, Yagi K. The occurrence of superoxide anion in the reaction of reduced phenazine methosulfate and molecular oxygen. Biochem Biophys Res Commun 1972;46:849-54.

25. Marcocci L, Packer L, Droy-Lefaix MT, Sekaki A, Gardès-Albert M. Antioxidant action of Ginkgo biloba extract EGb 761. Methods Enzymol 1994;234:462-75

26. Dinis TC, Maderia VM, Almeida LM. Action of phenolic derivatives (acetaminophen, salicylate, and 5-aminosalicylate) as inhibitors of membrane lipid peroxidation and as peroxyl radical scavengers. Arch Biochem Biophys 1994;315:161-9.

27. Oyaizu M. Studies on products of browning reactions: Antioxidative activities of products of browning reaction prepared from glucoamine. Jpn J Nutr 1986;4:307-15.

28. Shai LJ, Magano SR, Lebelo SL, Mogale AM. Inhibitory effects of five medicinal plants on rat alpha-glucosidase: Comparison with their effects on yeast alpha-glucosidase. J Med Plant Res 2011;5:2863-7.

29. Musa KY, Katsayal AU, Ahmed A, Mohammad A, Danmalam Z. Pharmacognostic investigation of the leaves of gisekia pharmacioides. Afr J Biotechnol 2006;5:956-7.

30. Kokoski CJ, Kokoski RJ, SLAMA FJ. Fluorescence of powdered vegetable drugs under ultraviolet radiation. J Am Pharm Assoc Am Pharm Assoc 1958;47:715-7.

31. Deb J, Dash GK. Pharmacognostical studies on stem bark of Acacia ferruginea DC. Pharmacia Lettre 2014;6:61-6.

32. Ansari SH. Essential of Pharmacognosy. $1^{\text {st }}$ ed. New Delhi: Birla Publications Pvt. Ltd.; 2007.

33. Ordonez AA, Gomez JD, Vattuone MA, Isla MI. Antioxidant activities of Sechium edule (Jacq). Food Chem 2006;97:452-8.

34. Wintola OA, Afolayan AJ. Phytochemical constituents and antioxidant activities of the whole leaf extract of Aloe ferox mill. Pharmacogn Mag 2011;7:325-33

35. Duraiswamy B, Singanan M, Varatarajan V. Physicochemical, phytochemicals and antioxidant evaluation of Guazuma ulmifolia fruit. Int J Pharm Pharm Sci 2018;10:87-91.

36. Nwaleaego NL, Chibuike OK, Chukwugekwu EM, Marylyn AC, Ngozi EI, Chukwunonye ER. In vitro antioxidant and free radical scavenging potential of methanolic extracts of Uvaria chamae leaves and roots. Int J Pharm Pharm Sci 2019;11:67-71.

37. Rahman MM, Khan FE, Das R, Hossain MA. Antioxidant activity and total phenolic content of some indigenous fruits of Bangladesh. Int Food J Res 2016;23:2399-404.

38. Miliauskas G, Venskutonis PR, van Beek TA. Screening of radical scavenging activity of some medicinal plants and aromatic plant extract. Food Chem 2004;85:231-7.

39. Macheix JJ, Fleuriet A. Phenolic acids in fruits. In: Rice-Evans CA, Packer L, editors. Flavonoids in Health and Disease. New York: Marcel Dekker Inc.; 1998.

40. Dey P, Chaudhuri TK. Antioxidant capacity of $N$. indicum: A correlation study using principal component analysis and multivariate statistical approach. Int J Pharma Pharm Sci 2013;5:931-7.

41. Wang RJ, Hu ML. Antioxidant capacities of fruit extracts of five mulberry genotypes with different assays and principal components analysis. Int J Food Prop 2011;14:1-8.

42. Ghosal M, Mandal P. Phytochemical screening and antioxidant activities of two selected 'Bihi' fruits used as vegetables in Darjeeling Himalaya. Int J Pharm Pharm Sci 2012;4:567-74. 